\title{
Indicators for measurement and improvement of the quality of family planning programs: The Philippines, 1997-1998
}

Population Council

Follow this and additional works at: https://knowledgecommons.popcouncil.org/departments_sbsr-rh

Part of the Demography, Population, and Ecology Commons, Family, Life Course, and Society Commons, International Public Health Commons, and the Women's Health Commons How does access to this work benefit you? Let us know!

\section{Recommended Citation}

"Indicators for measurement and improvement of the quality of family planning programs: The Philippines, 1997-1998," Policy brief. Washington, DC: Population Council, 2017. 


\section{INDICATORS FOR MEASUREMENT AND IMPROVEMENT OF THE QUALITY OF FAMILY PLANNING PROGRAMS: THE PHILIPPINES, 1997-1998}

Quality is a critical dimension of health service provision. Our aim is to highlight the creation and use of indicators for quality of care to enhance the achievement of the reproductive health (RH) goals in the Philippines and beyond.

\section{BACKGROUND}

The Philippine government has adopted a policy called the Responsible Parenthood and Reproductive Health Act (RPRH) in support of modern family planning (FP) and improved $\mathrm{RH}$. This includes the goal of ensuring 6 million women access to modern contraception. Though the policy does not refer to abortion, it faces stiff opposition from domestic anti-abortion, religiously conservative groups, which has stalled the full implementation of the policy through court appeals.

Over ten years prior to the passage of the RPRH Act, researchers in the Philippines conducted studies to assess the quality of FP services and care received. The study of quality in FP employs a framework that includes its determinants and effects, and incorporates fundamental elements that reflect clients' experience of services. Included among these fundamental elements is the concept of choice; namely, a client's ability to receive options for methods of family planning.

In response to the need of program managers to understand the quality of services at the field level, the Situation Analysis (SA) approach was developed. The SA is a field-level assessment of quality of services, meaning the readiness of $\mathrm{FP} / \mathrm{RH}$ programs to deliver services of good quality, and the quality of care, meaning the healthcare experience received by clients. SA provides managers information on those aspects over which they have control and about which they can make programmatic changes in order to ensure good quality of care.

Good care cannot be given or received when the enabling conditions do not exist. However, readiness alone is no guarantee that good care will be provided; readiness to provide an IUD is irrelevant if an IUD is not the right choice for a prospective client.

The conceptual model used in this study in the Philippines reflects the framework described above, placing the focus on multiple stages of care. Policy makers must set the appropriate context for program orientation and service delivery, facilities must be ready to provide

\section{RECOMMENDATIONS}

\section{Philippine Policy}

- The Administration intends to provide 6 million women, emphasizing those living below the poverty line, access to contraception. The evidence in our study suggests that quality of care is equally as important as increased access to and coverage of contraceptive services.

- Family planning networks should increase attention to quality of care monitoring to ensure a greater quality of care received by the client.

- Evidence suggests that contraceptive prevalence does not automatically meet reproductive health goals, an emphasis on improved quality of care could lead to stronger outcomes to support modern reproductive health priorities.

- The link between quality of service and quality of care needs to be further examined. Our evidence suggests a knowledge gap between the two in terms of readiness and delivery of contraception. 
services of good quality, and providers must have all resources required to serve their clients. At the end of this causal chain, facility users should receive good quality care. However, relatively little is known about how and why readiness affects client-provider interactions.

\section{DATA AND METHODS}

In the 2013 Demographic and Health Survey (DHS), the contraceptive prevalence rate among married women in the Philippines was $38 \%$. Almost $18 \%$ of women had an unmet need for contraception, and the total fertility rate was 3.0 births per woman. These figures reflect a gradual improvement in the level of family planning development from the same survey conducted in 1998 , when $24.6 \%$ of women had an unmet need for contraception, and the total fertility rate was 3.7 births per woman.

The program in the Philippines was organized to provide services for four contraceptive methods: the pill, IUD, injectable, and condom. Among all women surveyed, $19 \%$ used the pill as the primary method of contraception. This was followed by injectables (3.7\%), the IUD (3.5\%), and condoms. For comparison, $17.5 \%$ used a traditional method (e.g. rhythm or withdrawal).

In this study, we defined choice at the Service Delivery Point (SDP) level as a facility's readiness to provide these four reversible method choices. Three binary variables to track the SDPs were used: the presence of a trained provider, commodities in stock, and required equipment. A sum of 3 for a method meant the given SDP was "ready to provide" that method. A second variable was assigned each SDP to track the number of methods considered ready to provide, ranging from 0 (no methods ready) to 4 (all methods).

At the client level, four binary indicators were used based on client responses to exit surveys. The
Table 1: SDP Readiness to provide various FP methods, $\mathrm{n}=$ 70, Feb-March 1997

\begin{tabular}{|l|c|c|c|c|c|}
\hline $\begin{array}{l}\text { Item of } \\
\text { Readiness }\end{array}$ & $\begin{array}{c}\text { Condom } \\
(\%)\end{array}$ & $\begin{array}{c}\text { PIII } \\
(\%)\end{array}$ & $\begin{array}{c}\text { IUD } \\
(\%)\end{array}$ & $\begin{array}{c}\text { Injectable } \\
(\%)\end{array}$ & $\begin{array}{c}\text { All } \\
\text { Methods } \\
(\%)\end{array}$ \\
\hline $\begin{array}{l}\text { At least one } \\
\text { trained provider }\end{array}$ & 86 & 87 & 79 & 74 & 59 \\
\hline $\begin{array}{l}\text { Method in } \\
\text { Supply }\end{array}$ & 99 & 99 & 99 & 96 & 93 \\
\hline $\begin{array}{l}\text { Equipment } \\
\text { Available }\end{array}$ & N/A & N/A & 47 & 81 & 41 \\
\hline $\begin{array}{l}\text { All of the Above } \\
\text { 3 Items }\end{array}$ & 84 & 86 & 40 & 66 & 26 \\
\hline
\end{tabular}

questions used to generate the indicators are included on the following page (see Table 2). This measure is intended to reflect the degree of choice received by the client.

The research included two SAs spaced several months apart (March 1997 \& Aug 1997) and one client-level analysis gathered from surveys of clients who had visited SDPs included in the second SA. The analysis presented is a descriptive comparison of the results.

\section{RESULTS}

\section{SDP Readiness}

The first SA revealed a high proportion of SDPs with all methods available (93\%), but a lack of required equipment (41\%) and trained providers (59\%) (see Table 1). This resulted in just $26 \%$ of SDPs that were ready to provide full and effective choice of method. This figure increased to $43 \%$ following the second SA, thanks in large part to an increase in the percentage of trained providers (59\% to 83\%) (see Figure 1).

Figure 1: Percent of Facilities Ready to Provide Indicator for All Contraceptive Methods, Mar and Aug 1997

At Least One Trained Provider

Method Available

Equipment Available

Full Readiness
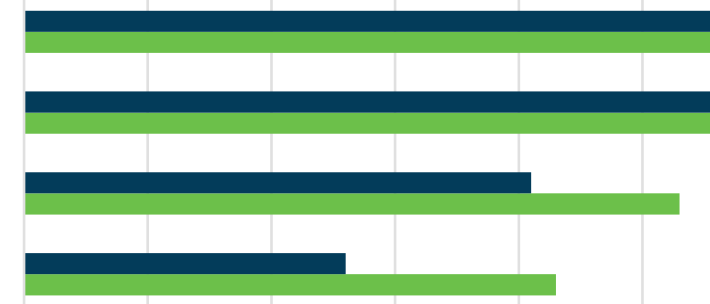

0

10 20 30 40

• Mar 1997 ( $\mathrm{n}=70) \quad$ aug $1997(\mathrm{n}=76)$ 


\begin{tabular}{l}
\hline Table 2: Percent of clients receiving choice of method (all \\
\begin{tabular}{|l|c|}
\hline Client Choice of Method & \% Received \\
\hline Given Choice Method & 99 \\
\hline Did not Have a Method Promoted & 91 \\
\hline Told about Another Method & 67 \\
\hline Asked Type of FP Method Preferred & 93 \\
\hline Received Full Choice & 54 \\
\hline
\end{tabular}
\end{tabular}

\section{Client Choice}

The client exit surveys revealed that clients received a full choice roughly $54 \%$ of the time. Only two-thirds of clients were told about an alternative method if the first option was unavailable. The other three indices yielded stronger positive responses on choice criteria (see Table 2).

\section{Relationship between SDP Readiness \& Client Choice}

Interestingly, there was no significant difference in receipt of full choice among facilities with varying degrees of readiness. If fact, among facilities that were fully ready (all four methods), only $51 \%$ of clients experienced full choice, almost the same as the average level of choice received among all facilities (54\%).

\section{DISCUSSION}

While readiness is a necessary condition for the provision of good quality care, it alone is not sufficient to guarantee quality. This suggests there are unidentified factors at play; the details and potential meanings of client-provider interaction remain for now unresolved.

The research underscores the importance of a composite index when measuring quality. Any given indicator by itself can yield a highly positive response, thus leading researchers to falsely conclude that the overall quality of care is sufficient. However, if other equally important indicators are incorporated, a different conclusion may be drawn, demonstrating a need for improved quality of care. In devising measures of quality, multiple indicators are needed to capture all important aspects of care, and then target the resultant weak areas.

In the "Recommendations" section, we connect the results of this study with relevant applications in the field. In the case of the Philippines, the evidence suggests the need for more quality of care monitoring in addition to expanded access to contraceptives. Investment in counseling of clients and training of providers will support the achievement of the goal of reaching 6 million women.

The RPRH Act is a meaningful step toward achieving the United Nations Sustainable Development Goals. The national Department of Health of the Philippines should continue to make improved FP a major public health priority, particularly in the face of continued opposition. We hope this study stimulates further research on the client-provider relationship and encourages policymakers to focus on client counseling, choice, and education in addition to infrastructure as a means of meeting women's FP needs.

\section{REFERENCES}

1. "Facts on Barriers to Contraceptive Use in the Philippines." May, 2010. Guttmacher Institute. https://www.guttmacher.org/fact-sheet/factsbarriers-contraceptive-use-philippines

2. Philippine Statistics Authority - PSA and ICF International. 2014. Philippines National Demographic and Health Survey 2013. Manila, Philippines: PSA and ICF International. - See more at:

http://dhsprogram.com/publications/publicationFR294-DHS-Final-

Reports.cfm\#sthash.d2s2N93e.dpuf

3. Saumya RamaRao \& Anrudh K. Jain. 2016. "Constructing indicators for measurement and improvement of the quality of family planning programs: An example using data on choice from the Philippines, 1997-1998," in Leisher SH, Sprockett A, Longfield K, and Montagu D (eds.), Quality Measurement in Family Planning: Past, Present, Future: Papers from the Bellagio Meeting on Family Planning Quality, October 2015. Oakland, CA: Metrics for Management, pp. 47-61.

\footnotetext{
This brief is based on the article, Constructing indicators for measurement and improvement of the quality of family planning programs: An example using data on choice from the Philippines, 1997-1998, prepared by Saumya RamaRao and Anrudh K. Jain for the Measuring and Monitoring Quality of Services and Quality of Care project funded by a grant from the David and Lucile Packard Foundation to the Population Council. We gratefully acknowledge the support of the Foundation to continue research on the state of quality of care and the communications support of Peter Blum in preparation of this brief.
} 